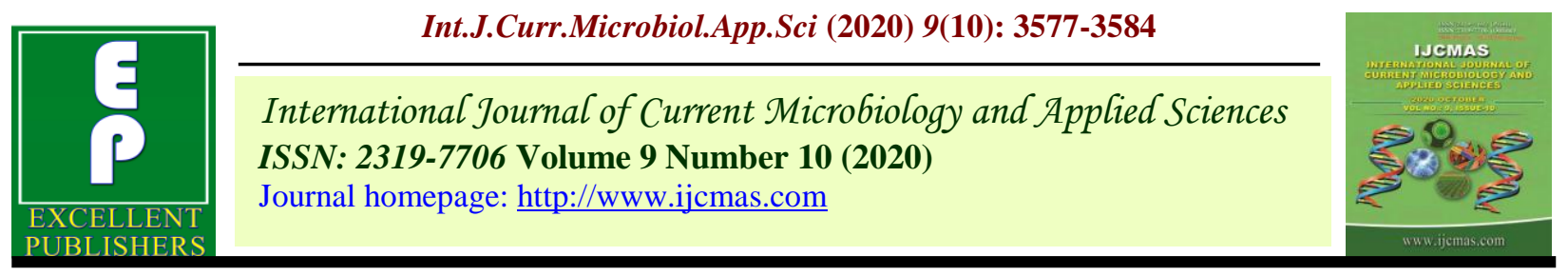

Original Research Article

https://doi.org/10.20546/ijcmas.2020.910.413

\title{
Effect of Different Growing Conditions on Rooting and Growth of Stem Cuttings in Pomegranate (Punica granatum L.)
}

\author{
Sachin Kumar ${ }^{1 *}$, Satya Prakash ${ }^{1}$, Arvind Kumar1, Vipin Kumar ${ }^{1}$, \\ Pooran Chand ${ }^{2}$ and B. P. Dhyani ${ }^{3}$ \\ ${ }^{1}$ Department of Horticulture, ${ }^{2}$ Department of Genetics and Plant Breeding, ${ }^{3}$ Department of \\ Soil Science, Sardar Vallabhbhai Patel University of Agriculture and Technology, \\ Modipuram, Meerut (Uttar Pradesh), India \\ *Corresponding author
}

\section{A B S T R A C T}

Keywords

Pomegranate, Hard wood cutting and Growing conditions

Article Info

Accepted:

26 September 2020

Available Online:

10 October 2020
The present study entitled "Effect of different growing conditions on rooting and growth of stem cuttings in pomegranate (Punica granatum L.)", was conducted at Horticultural Research Centre (HRC) of Sardar Vallabhbhai Patel University of Agriculture and Technology, Meerut, Uttar Pradesh, during 2016 and 2017. The experiment was laid out using RBD with two growing conditions. The stem cuttings when grown in under shade had recorded significantly earliest sprouting and highest survival, shoot and root growth of stem cutting. However, among the stem cuttings, poor survival, shoot and root growth of stem cutting were observed grown in open condition.

\section{Introduction}

Pomegranate belongs to the family Punicaceae. The genus 'Punica' has two species viz., Punica granatum (cultivated pomegranate) and Punica protopunica (wild pomegranate). Pomegranate is basically diploid in nature with $2 \mathrm{n}=2 \mathrm{x}=16,18$ chromosomes (Smith, 1979, Darlington and Janakiammal, 1945). The number of chromosome in the somatic complements of cvs.,Dholka, Ganesh, Kandhari, Muscat White and Patiala were found to be $2 n=16$, while the cv. Double Flower (ornamental type) had $2 \mathrm{n}=18$ (Nath and Randhawa, 1959a). The chromosome number in cvs.
Vellodu and Kashmiri were found to be $2 \mathrm{n}=2 \mathrm{x}=18$ (Raman, et al., 1963). Botanically the type of pomegranate fruit is berry balausta. The pomegranate (Punica granatum L.) is believed to be originated from Iran (Primary centre of Origin). Besides, it is widely prevalent in Afghanistan, Pakistan and India, the Secondary Centers of Origin (DeCandolle, 1967). The usage of pomegranate is deeply embedded in human history with references in many ancient cultures about its use in food and medicine (Holland et al., 2009). It is one of the oldest known edible fruits and is associated with ancient civilizations of the Middle East. India ranks first in the world with respect to pomegranate 
area and production, but Iran is the largest exporter. During 2015, pomegranate in the country was cultivated over 0.19689 million ha with annual production of 2.30644 million tonnes (Saxena, 2017). Quality of planting material is always prime need to the fruit growers. Therefore, it is necessary to produce quality planting material for distribution among the fruit growers. For the purpose, a rapid method for multiplication of planting material of pomegranate is needed to obtain good quality plants (Frey et al., 2006). The pomegranate is propagated by seeds, cuttings, layering, off shoots and grafting. Of these methods of propagation, cutting is the most used form of multiplication in pomegranate. Propagation by stem cuttings are simple, easily to perform, rapid, economic and works well. New plants developed from stem cutting are true to type and uniform in growth (Owais, 2010 and Saroj et al., 2008). Pomegranate can be propagated from softwood or hardwood cuttings. Hardwood cuttings are the preferred means of propagation, but softwood cuttings collected in early fall can be used with varying degrees of success. The cuttings collected at the end of February had higher rooting potential than those taken at the beginning of October. Cuttings should be maintained at a temperature between $21-27^{\circ} \mathrm{C}$ during the day and night time (Sandhu et al., 1991). Besides pre-planting treatments, the growing condition also significantly affected the performance of stem cutting (Owen 2007 and Kumawat, 2010). Higher success, survival and better shoot and root growth were observed in stem cuttings when grown in net house or under controlled condition (Atayi, 2011).

\section{Materials and Methods}

The present study was conducted at Horticultural Research Centre (HRC) and PG laboratory of department of Horticulture, Sardar Vallabhbhai Patel University of
Agriculture and Technology, Meerut (UP) during 2016 and 2017.The university is situated on Meerut- Roorkee road (Near Modipuram), about $11 \mathrm{~km}$ away from the Meerut city. Geographically, experimental field is located at $29.01^{\circ}$ North latitude, $77.45^{\circ}$ East longitude and at an altitude of 237.75 meter above the mean sea level.

The climate of this region is sub-tropical with maximum temperature of about $42^{\circ} \mathrm{C}$ during summer (April to October) and a minimum temperature of about $7^{\circ} \mathrm{C}$ during winter (November to March). Frost occasionally occurs in this region during winter from December to February. The monsoon generally begins during the last week of June and ceases by the end of September. The average annual rainfall in the region is about $862.7 \mathrm{~mm}$ and the annual relative humidity varies from 67 to 83 percent. The mother plants from which stem cuttings were taken were maintained healthy following proper orchard management practices. The pest and disease free healthy mother plants of pomegranate having uniform size, vigour, age and growing in full sunlight were selected for preparing the stem cuttings.

The coloured polybags of 22:13:10 $\mathrm{cm}$ size were used for the study.

The propagation study was carried out under two growing conditions as given follows:

Open condition

Shade condition (net house).

For this purpose, two similar sets of experimental material were prepared. One set of experimental material was kept in open condition and another set was kept under net house in which there was a provision of 50 per cent shade. First of all, one-year old branches were detached from mother plant of cv. Ganesh with the help of sharp secateur. The central and basal portion of selected 
shoot was used for preparing the stem cutting. Eighteen centimetre long stem cuttings having pencil thickness $(0.80-1.00 \mathrm{~cm})$ were prepared. Slant cut at the distal (terminal) end, while straight cut at proximal (basal) end was given in each cutting. At least 5 functional buds were included in each stem cutting.

The basal cut was made just below a node and the terminal cut $1.5 \mathrm{~cm}$ above a node. Just after preparation of stem cuttings, proximal end of cuttings was dipped in water in order to protect them against desiccation. At least $2 / 3^{\text {rd }}$ portion of each cutting was inserted in the rooting media leaving two buds above the rooting media. Just after planting of stem cutting in polybag, watering was done with the help of sprinkler cane.

After planting one set of experimental material was kept in open condition and another set was kept in shade (net house). The stem cuttings were planted in the month of February during both the years of study.

\section{Results and Discussion}

A propagation study entitled "Effect of chemical, wounding and rooting media treatments on rooting and growth of stem cutting in pomegranate (Punica granatum L.) under different growing conditions", was conducted at Horticultural Research Centre (HRC) of Sardar Vallabhbhai Patel University of Agriculture and Technology, Meerut, Uttar Pradesh-250110 during 2016 and 2017 with a view to find out the impact of bio-regulator (IBA), nutrient (Boron), wounding, rooting media and growing conditions on rooting and growth of stem cutting in pomegranate.

Different quantitative and qualitative attributes pertaining to propagation were recorded during the course of investigation. The results obtained on different parameters are summarized under the following heads (Table 1 and 2).

\section{Days taken for bud sprouting}

Days taken for bud sprouting in stem cuttings grown under open and shade conditions were differed significantly during both the years of study. The stem cuttings grown under shade had early sprouting (12.86 days) than cuttings grown in open condition (14.16 days) during both the years of investigation. In comparison to open condition, bud sprouting was advanced by 1.30 days grown under shade condition.

\section{Sprouting percentage}

Data on sprouting percent was recorded after 3 weeks of planting of stem cuttings. The data revealed significant effect of IBA, boric acid, wounding and rooting media on sprouting percent in stem cuttings of pomegranate. Growing condition also significantly affected the sprouting percentage in cutting treated with different treatment.

Data also revealed that sprouting percentin cuttings of all treatments was higher when grown under shade than open condition during both the years of investigation $(97.8 \%$ and $98.0 \%$ )

\section{Survival percentage}

Data recorded on survival percent also revealed that irrespective of treatments, survival of stem cutting was significantly better under shade (80.89\%) than open condition $(73.83 \%)$ during both the years of investigation. A maximum of $9.56 \%$ increase in survival percent was recorded in cuttings grown under shade condition over open condition.

\section{Number of shoots in stem cutting}

Irrespective of treatments, the stem cutting grown under shade had significantly higher number of shoots (4.77) than cuttings grown 
in open conditions (4.31) during both the years of investigation. A maximum of $10.67 \%$ increase in number of shoot was recorded in cuttings grown under shade condition over open condition.

\section{Mean shoot length}

Irrespective of treatments and rooting media, the stem cuttings grown in shade had significantly greater mean shoot length (49.77 $\mathrm{cm})$ than those cuttings grown in open condition $(42.79 \mathrm{~cm})$. A maximum of $16.31 \%$ increase in mean shoot length was recorded in cuttings grown under shade condition over open condition.

\section{Length of longest shoot}

The length of longest shoot per cutting was found to be significantly higher all treated cuttings when grown under shade condition $(78.12 \mathrm{~cm})$ than open condition $(72.38 \mathrm{~cm})$ during both the years of study. A maximum of $7.93 \%$ increase in length of longest shoot was recorded in cuttings grown under shade condition over open condition.

\section{Diameter of longest shoot}

Irrespective of treatments, the cuttings grown under shade had significantly higher diameter $(3.99 \mathrm{~mm})$ of longest shoot than those grown in open condition $(3.60 \mathrm{~mm})$ during both the years of investigation. A maximum of $10.83 \%$ increase in diameter of longest shoot was recorded in cuttings grown under shade condition over open condition.

\section{Total number of leaves}

Growing condition also significantly influenced the production of leaves in cutting. Irrespective of treatments, the stem cuttings grown in shade had significantly higher number of leaves per cutting (225.39) than those cuttings which were grown in open condition (201.65) during both the years of investigation. A maximum of $11.77 \%$ increase in total number of leaves was recorded in cuttings grown under shade condition over open condition.

\section{Total leaf area}

The stem cuttings treated different treatments and grown in different growing conditions had significantly different leaf area. When stem cuttings grown under shade condition significantly higher leaf area of stem cutting $\left(1005.43 \mathrm{~cm}^{2}\right)$ was recorded than those cuttings grown in open condition (931.42 $\mathrm{cm}^{2}$ ) during both the years. A maximum of $7.94 \%$ increase in total leaf area was recorded in cuttings grown under shade condition over open condition.

\section{Fresh weight of shoot}

Fresh weight of shoot of stem cutting was also affected significantly by growing conditions. The stem cuttings of different treatments when grown under shade condition had recorded significantly higher fresh weight of shoot (20.45 g) than cuttings grown in open condition (17.98 g) during both the years. A maximum of $13.73 \%$ increase in fresh weight of shoot was recorded in cuttings grown under shade condition over open condition.

\section{Dry weight of shoot}

The dry weight of shoot was found to be significantly maximum in treated cuttings when grown under shade condition (14.77 g) than those treated cuttings grown in open condition $(11.82 \mathrm{~g})$ during both the years of study. A maximum of $24.95 \%$ increase in dry weight of shoot was recorded in cuttings grown under shade condition over open condition.

\section{Number of primary root}


The data further revealed that stem cuttings grown in shade condition had significantly higher number of root (34.97) than those cuttings grown in open condition (33.34) during both the years. A maximum of $4.89 \%$ increase in number of primary root was recorded in cuttings grown under shade condition over open condition.

\section{Mean root length}

Significantly higher mean root length of cutting was recorded in cuttings grown under shade condition $(25.40 \mathrm{~cm})$ over open condition $(22.00 \mathrm{~cm})$ during both the years of study. A maximum of $15.45 \%$ increase in mean root length was recorded in cuttings grown under shade condition over open condition.

Table.1 Effect of growing conditions on rooting and growth of stem cutting in pomegranate

\begin{tabular}{|l|l|c|c|c|}
\hline S. No. & & $\begin{array}{c}\text { Open } \\
\text { condition }\end{array}$ & $\begin{array}{c}\text { Shade } \\
\text { condition }\end{array}$ & CD(5\%) \\
\hline $\mathbf{1 .}$ & Days taken for bud sprouting & 14.16 & 12.86 & 0.092 \\
\hline $\mathbf{2 .}$ & Sprouting percentage (\%) & 96.50 & 97.78 & 1.315 \\
\hline $\mathbf{3 .}$ & Survival percentage (\%) & 73.83 & 80.89 & 2.088 \\
\hline $\mathbf{4 .}$ & Number of shoots & 4.31 & 4.77 & 0.072 \\
\hline $\mathbf{5 .}$ & Mean shoot length $(\mathrm{cm})$ & 42.79 & 49.77 & 0.556 \\
\hline $\mathbf{6 .}$ & Length of longest shoot $(\mathrm{cm})$ & 72.38 & 78.12 & 0.718 \\
\hline $\mathbf{7 .}$ & Diameter of longest shoot $(\mathrm{mm})$ & 3.60 & 3.99 & 0.042 \\
\hline $\mathbf{8 .}$ & Total number of leaves & 201.65 & 225.39 & 2.418 \\
\hline $\mathbf{9 .}$ & Total leaf area $\left(\mathrm{cm}^{2}\right)$ & 931.42 & 1005.43 & 17.693 \\
\hline $\mathbf{1 0 .}$ & Fresh weight of shoot $(\mathrm{g})$ & 17.98 & 20.45 & 0.216 \\
\hline $\mathbf{1 1 .}$ & Dry weight of shoot $(\mathrm{g})$ & 11.82 & 14.77 & 0.224 \\
\hline & & & & \\
\hline & & & & \\
\hline
\end{tabular}

Table.2 Effect of growing conditions on rooting of stem cutting in pomegranate

\begin{tabular}{|l|l|c|c|l|}
\hline S. No. & & $\begin{array}{c}\text { Open } \\
\text { condition }\end{array}$ & $\begin{array}{c}\text { Shade } \\
\text { condition }\end{array}$ & CD(5\%) \\
\hline 1. & Number of primary root & 33.34 & 34.97 & 0.219 \\
\hline $\mathbf{2 .}$ & Mean root length $(\mathrm{cm})$ & 22.00 & 25.40 & 0.207 \\
\hline $\mathbf{3 .}$ & Length of longest root $(\mathrm{cm})$ & 29.73 & 36.22 & 0.271 \\
\hline $\mathbf{4 .}$ & Mean root diameter $(\mathrm{mm})$ & 1.19 & 1.35 & 0.010 \\
\hline $\mathbf{5 .}$ & Diameter of longest root $(\mathrm{mm})$ & 2.04 & 2.33 & 0.018 \\
\hline $\mathbf{6 .}$ & Fresh weight of root $(\mathrm{g})$ & 6.84 & 7.70 & 0.086 \\
\hline $\mathbf{7 .}$ & Dry weight of root $(\mathrm{g})$ & 4.68 & 5.43 & 0.078 \\
\hline $\mathbf{8 .}$ & Per cent dry weight of root & 66.69 & 68.71 & 0.635 \\
\hline
\end{tabular}




\section{Length of longest root}

Irrespective of treatments and rooting media, the stem cuttings grown in shade had significantly higher mean length of longest root $(36.22 \mathrm{~cm})$ than those cuttings grown in open condition $(29.73 \mathrm{~cm})$. A maximum of $21.82 \%$ increase in length of longest root was recorded in cuttings grown under shade condition over open condition.

\section{Mean root diameter}

Irrespective of treatments, the cuttings grown under shade had significantly higher mean diameter of root $(1.35 \mathrm{~mm})$ than those grown in open condition $(1.19 \mathrm{~mm})$ during both the years of investigation. A maximum of $13.44 \%$ increase in mean root diameter was recorded in cuttings grown under shade condition over open condition.

\section{Diameter of longest root}

Irrespective of treatments, the stem cuttings grown under shade had significantly higher diameter of longest root $(2.33 \mathrm{~mm})$ than cuttings grown in open conditions $(2.04 \mathrm{~mm})$ during both the years of investigation. A maximum of $14.21 \%$ increase in diameter of longest root was recorded in cuttings grown under shade condition over open condition.

\section{Fresh weight of root}

Fresh weight of root of stem cutting was also significantly affected by growing conditions. The stem cuttings of different treatments when grown under shade condition had recorded significantly higher fresh weight of root $(7.70 \mathrm{~g})$ than open condition $(6.84 \mathrm{~g})$ during both the years.

A maximum of $12.57 \%$ increase in fresh weight of root was recorded in cuttings grown under shade condition over open condition.

\section{Dry weight of root}

Dry weight of root of stem cutting was also significantly affected by growing conditions. Significantly higher dry weight of root (5.43 g) of stem cuttings was recorded in shade condition over open condition (4.68 g) during both the years. A maximum of $16.02 \%$ increase in dry weight of root was recorded in cuttings grown under shade condition over open condition.

\section{Percent dry weight of root}

Data also revealed that irrespective of treatments, percent dry weight of root of stem cutting was significantly higher under shade $(68.71 \%)$ than open condition (66.69\%) during both the years of investigation. A maximum of $3.02 \%$ increase in percent dry weight of root was recorded in cuttings grown under shade condition over open condition.

\section{Sprouting of cutting}

Growing condition also affected the bud sprouting in the present study. The earliest bud sprouting was recorded in cuttings grown under shade as compared to open condition, Desai and Patil (1984) had also observed that greenhouse induce early sprouting for vegetative propagation. The earliest sprouting under shade condition was also reported by Jinturkar and Narwadkar (1989). This might be due to controlled environmental factors such as temperature, humidity and sunlight. The shade condition provides totally or partially controlled environmental condition, which helps early completion of physiological process and growth of cuttings (Kumawat $e t$ al., 2010 and Owen, 2007).

\section{Survival of stem cutting}

In the present study, shade has favourable effect on survival of cutting as compared to 
open condition. A maximum of $80.89 \%$ higher success of stem cutting was recorded in shade condition over open condition. These results are in accordance with the finding of Kumawat et al., (2010) who has recorded maximum success of $80.70 \%$ when cuttings were grown under Poly house x 1500 ppm IBA, while minimum percentage success of cuttings (50.38) was recorded under Open field condition x Control. He further observed that survival of cuttings was significantly higher in poly house condition than Net house and Control, while minimum percentage of success of cuttings (65.90) was recorded in Open field condition.

\section{Vegetative and root growth of stem cutting}

In the present study, higher shoot and root growth in stem cutting was also found to be influenced significantly when cuttings were grown in shade as compared to open condition. Similar increase in shoot and root growth was also reported by Kumawat et al., (2010), who has recorded higher vegetative and root growth (i.e. number of shoot, length of shoot, total number of shoot, fresh weight of shoot, dry weight of shoot, number of root, diameter of root, longest root length, fresh weight of root and dry matter \% of root) in cuttings grown in net house than control condition (open condition). The favourable effect of shade condition on vegetative and root growth in stem cutting of pomegranate was also reported by other researchers (Kumari, 2014; Hussain et al., 2012; Singh 2017 and Atayi, 2011). In other crop (Bougainvillea) also, higher shoot and root growth was observed when stem cuttings were grown in shaded polythene tents (Singh and Rathore 1977).

The better growth of cuttings grown in controlled condition may be because of the fact that shade condition provides favourable environmental condition (i.e. temperature, light and humidity) which resulted in early completion of physiological process and growth of cuttings (Owen, 2007; Desai and Patil, 1984; Jinturkar and Narwadkar, 1989; Bose et al., 1991 and Kumawat et al., 2010). On the other hand, poor growth of cuttings recorded in open condition might be attributed to adverse climate condition prevailing in control (open) condition (Kumawat et al., 2010).

\section{References}

Atayi, A. R. (2011). Effect of growth regulator on rooting and sprouting of pomegranate (Punica granatum L.) cutting under greenhouse condition. M.Sc. thesis. submitted to University of Agricultural Sciences, Bangalore. 93p.

Bose, T. K., Mitra, S. K. and Sadhu, M. K. (1991). External factor affecting rooting of cuttings. Propagation of tropical and sub-tropical Horticultural crop, pp. 37.

Darlington, D. C. and Janakiammal, E. K. (1945). Chromosome atlas of cultivated plants.

De Candolle, A. (1967). Orgin of Cultivated Plants. Hafner Publication, Co. New York and London Distribution Co, Lucknow (U. P.). 468: 237-240.

Desai, J. B. and Patil, V. K. (1984). Success of stone grafting in mango in glass house and in open. Punjab Hort. J.24(1/40): 7-10.

Holland, D., Hatib, K. and Bar-Yaakov, I. (2009). Pomegranate - Botany, horticulture and breeding. Hort. Rev., 35: 127-191.

Hussain, I., Khattak, A. M., Amin, N. U., Aman, F. and Sajid, M. (2012). Response of different pomegranate cuttings types to different environmental conditions. Sarhad J. Agric. 28(1): 15-18. 
Jinturkar, S. P. AND Narwadkar, P. R. (1989). Effect of environmental conditions on the success of epicotyl grafting in mango. ActaHorticulturae, (231): 252-255.

Kumari, K. R. (2014). Studies on The Effect of Iba and Rooting Media on Rhizogenesis of Cuttings of Pomegranate (Punica granatum L.) $\mathrm{Cv}$. Bhagwa under Shade Net Conditions. M.Sc. thesis. Submitted to Dr. Y. S. R. Horticultural University. 148p.

Kumawat, B. R., Kanpure, R. N., Tiwari, R., Baghel, B. S. and Barde, P. K. (2010). Rooting and growth of pomegranate cutting as influenced by environmental conditions and growth regulator. Ann. Pl. Soil Res., 12(1): 30-31.

Nath, N. and Randhawa, G. S. (1959a). Studies on cytology of pomegranate. Indian J. Hort. 16: 210-15.

Owais, S. J. (2010). Rooting response of five pomegranate varieties to indole butyric acid concentration and cuttings age. Pakistan journal of biological Sciences, 13(2): 51-55.

Owen, J. S. (2007). Environmental Effects on Stem-Cutting Propagation: A Brief Review. Combined Proceedings International Plant Propagators' Society. 57: 58-64.

Owen, J. S. (2007). Environmental Effects on Stem-Cutting Propagation: A Brief Review. Combined Proceedings International Plant Propagators' Society. 57: 58-64.
Raman, V. S., Kesavan, P. C., Manimekalai, G., Alikhan, W. M. and Rangaswami, S. R. (1963). Cytological studies in some tropical fruit plants - Banana, annona, guava and pomegranate, South Indian Horticulture, 11: 27-33.

Sandhu, A. S., Minhas, P. P. S., Singh, S. N. and Kambhoj, J. S. (1991). Studies on rhizogenesis in hardwood cutting of pomegranate. Indian J. Horti., 44(4): 302-304.

Saroj, P. L., Awasthi, O. P., Bhargava, R. and Singh, U. V. (2008). Standardization of pomegranate propagation by cutting under mist system in hot arid region. Indian J. Hort. 65(1): 25-30.

Saxena, M. (adviser horticulture) (2017). Ministry of Agriculture and Farmer Welfare Department of Agriculture, Cooperation and Farmer Welfare, Horticulture Statistics Division. p. 481.

Singh, I. P. and Rathore, S. V. S. (1977). Rooting and survival of bougainvillea cuttings as affected by maturity of wood and planting environments. Haryana J. Hort. Sci., 4: 201-203.

Singh, K. K. (2017). Effect of IBA concentrations on the rooting of pomegranate (Punica granatum L.) cv. Ganesh hardwood cuttings under mist house condition. International Journal of Horticulture and Floriculture5(4): 318-323.

Smith, P. M. (1979). Minor crops In: Evolution of crop plants (Ed. Simmonds, N.W.), Longman, p.320

\section{How to cite this article:}

Sachin Kumar, Satya Prakash, Arvind Kumar, Vipin Kumar, Pooran Chand and Dhyani, B. P. 2020. Effect of Different Growing Conditions on Rooting and Growth of Stem Cuttings in Pomegranate (Punica granatum L.). Int.J.Curr.Microbiol.App.Sci. 9(10): 3577-3584. doi: https://doi.org/10.20546/ijcmas.2020.910.413 